\title{
PENGAMBILAN KEPUTUSAN UNTUK PENENTUAN BIDANG KEAHLIAN SISWA/WI SMK SWASTA MULIA PRATAMA MEDAN DENGAN METODE PROMETHEE
}

\author{
${ }^{1}$ Nurmala Sridewi, ${ }^{2}$ Murdani \\ ${ }^{1}$ AMIK Widya Loka Medan, ${ }^{2}$ Universitas Budi Darma Medan \\ malaketaren1@gmail.com, murdanimkom@gmail.com
}

Received: August 25, 2021, Revised: September 16, 2021 Accepted: October 10, 2021

\begin{abstract}
Abstrak
Sistem pendukung keputusan merupakan sistem informasi interaktif yang menyediakan informasi, pemodelan dan pemanipulasian data. Sistem ini digunakan untuk membantu pengabilan keputusan dalam situasi yang semi terstruktur dan situasi tidak terstruktur. Sistem pendukung keputusan dibangun untuk mendukung solusi atas suatu masalah atau untuk mengevaluasi suatu peluang. Begitu pun untuk menentukan bidang keahlian pada SMK Swasta Mulia Pratama. Untuk menentukan bidang keahlian setiap siswa, maka dibutuhkan suatu metode promethee agar dapat memudahkan sekolah dalam menentukan bidang keahlian siswa/I tanpa harus mewawancarai secara langsung. Metode promethee ini sering disebut dengan metode penjumlahan terbobot. Konsep dasar metode promethe adalah mencari penjumlahan terbobot dari rating kinerja pada setiap alternatif pada semua atribut.
\end{abstract}

Kata kunci : Metode Promethee, sistem pendukung keputusan, kriteria bidang keahlian siswa/i

Abstract

Decision support system is an interactive information system that provides information, modeling and manipulating data. This system is used to assist decision making in semi-structured and unstructured situations. Decision support systems are built to support the solution to a problem or to evaluate an opportunity. Likewise, to determine the field of expertise at the Mulia Pratama Private Vocational School. To determine the area of expertise of each student, a promethee method is needed in order to make it easier for schools to determine the student's area of expertise without having to interview directly. The promethee method is often referred to as the weighted addition method. The basic concept of the promethe method is to find the weighted sum of the performance ratings for each alternative on all attributes.

Key words: Promethee method, decision support system, criteria for students' areas of expertise

\section{Pendahuluan}

Seiring perkembangan teknologi yang semakin luas, peran komputer semakin mendominasi bagi manusia dalam melakukan suatu pekerjaan. Komputer tidak hanya digunakan sebagai alat hitung, tetapi komputer digunakan untuk mengerjakan segala sesuatu yang biasa dikerjakan manusia. Untuk itu dibutuhkan sistem pendukung keputusan agar membantu menyelesaikan permasalahan. Begitu pula dalam menentukan bidang keahlian siswa/I SMK Mulia Pratama, dibutuhkan sistem pendukung keputusan agar membantu sekolah dalam menentukan bidang keahlian 
masing-masing siswa/i. penentuan bidang keahlian dapat dilakukan dengan memenuhi kriteria yang telah ditentukan sekolah. Adapun kriteria yang digunakan adalah administrasi perkantoran, rekayasa perangkat lunak, multimedia dan teknik sepeda motor. Kajian pokok dalam sistem pendukung keputusan adalah bagaimana menentukan bidang keahlian ke dalam komputer dan bagaimana mengambil keputusan berdasarkan metode yang dipilih. Untuk itu dibutuhkan metode promethee agar memudahkan sekolah dalam menentukan bidang keahlian siswa/i. metode promethe sering disebut dengan metode penjumlahan terbobot. Promethee adalah salah satu metode penentuan urutan atau prioritas dalam MCDM (Multi Criterion Decision Making) Penggunaan promethee adalah menentukan dan menghasilkan keputusan dari beberapa alternatif. Promethee berfungsi untuk mengolah data, baik data kuantatif dan kualitatif. Dimana semua data digabung menjadi satu dengan bobot penilaian yang telah diperoleh melalui penilaian atau survey.Metode Promethee mampu menjawab persoalan yang bersifat multikriteria dengan cara menentukan urutan (prioritas).[1]

\section{Sistem Pendukung Keputusan}

Sistem pendukung keputusan adalah Sistem informasi interaktif yangmenyediakan informasi, pemodelan, dan pemanipulasian data.Sistem ini digunakan untuk membantu pengambilan keputusan dalam situasi yang semi terstruktur dan situasi tidak terstruktur, dimana tidak seorang pun tahu secara pasti bagaimana keputusan seharusnya dibuat.[2]

Sistem pendukung keputusan tidak dimaksudkan untuk mengotomatisasikan pengambilan keputusan, tetapi untuk melakukan berbagai analisis menggunakan model-model yang tersedia. Sistem ini berbasis komputer yang dirancang untuk meningkatkan efektivitas pengambilan keputusan dalam memecahkan masalah yang bersifat semi terstruktur dan tidak terstruktur.

\section{Preference Rangking Organizationing Method for Enrichment Evaluation (Promethee)}

Promethee adalah suatu metode penentuan urutan (prioritas) dalam MCDM. Permasalah utama dalam metode ini adalah kesederhanaan, kejelasan dan kestabilan.[1] Dugaan dari dominasi kriteria yang digunakan dalam promethee adalah penggunaan nilai dalam hubungan outranking. Dalam Prometheeterdapat enam bentuk fungsi preferensi kriteria.Meskipun tidak bersifat mutlak, namun bentukbentuk ini cukup baik untuk beberapa kasus. [3] Untuk memberikan gambaran yang lebih baik terhadap area yang tidak sama, digunakan fungsi selisih nilai kriteria antara alternatif $H(d)$, dimana hal ini mempunyai hubungan langsung dengan fungsi preferensi P. Promethee berfungsi untuk mengolah data, baik data kuantitatif dan kualitatif sekaligus. Dimana semua data digabung menjadi satu dengan bobot penilaian yang telah diperoleh melalui penilaian atau survey.

Ada beberapa langkah dalam penyelesaian perhitungan dengan metodePrometheeadalahsebagai berikut:

1. Penentuan alternatif - alternatif nilai dari data karyawan terhadap criteria -kriteria yang telah ditetapkan sebelumnya.

2. Menentukan tipe fungsi preferensi dan nilai preferensi

3. Perhitungan indeks preferensi.

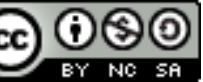

JURNAL WIDYA This work is licensed under a Creative Commons Attribution-NonCommercialShareAlike 4.0 International License. 
4. Perhitungan arah preferensi dipertimbangkan berdasarkan nilai indeks leaving flow $\left(\Phi^{+}\right)$, entering flow ( $\left.\Phi^{-}\right)$, dan net flow.

Langkah-langkah metode Promethee adalah sebagai berikut:

1. Menentukan Tipe fungsi preferensi criteria:

Criteria umum / tipeI (Usual Criterion ) [4]

$\mathrm{H}(\mathrm{d})=\quad 0 \mathrm{jika} \mathrm{d}=0$

1 jika d $\neq 0$.

Pada criteria ini tidak beda antara a dan b jika dan hanya jika $f(a)=f(b)$, apabila nilai criteria pada masing - masing alternative memiliki nilai berbeda, pembuat keputusan mempunyai preferensi mutlak untuk alternative memiliki nilai yang lebih baik

2. Perhitungan nilai indeks :

$\mathrm{k}$

$\delta(\mathrm{a}, \mathrm{b})=\sum \pi \mathrm{P}_{\mathrm{i}}(\mathrm{a}, \mathrm{b}) ; \forall \mathrm{a}, \mathrm{b} \varepsilon \mathrm{A}$

$\mathrm{i}=1$

3.Perhitungan arah preferensi dipertimbangkan berdasarkan nilai indeks leaving flow $\left(\Phi^{+}\right)$, entering flow $\left(\Phi^{-}\right)$, dan net flow mengikuti persamaan:

$$
\begin{aligned}
& \text { Leaving flow: } \Phi^{+}(\mathrm{a})=\frac{1}{\mathrm{n}-1} \sum \delta(\mathrm{a}, \mathrm{x}) \mathrm{x} \varepsilon \mathrm{A} \ldots \\
& \text { Entering flow: } \Phi^{-}(\mathrm{a})=\frac{1}{\mathrm{n}-1} \sum \delta(\mathrm{x}, \mathrm{a}) \mathrm{x} \varepsilon \mathrm{A} \\
& \text { Net flow } \quad: \Phi(\mathrm{a})=\Phi^{+}(\mathrm{a})-\Phi^{-}(\mathrm{a}) . .
\end{aligned}
$$

\section{Analisa dan Hasil Pembahasan}

Untuk menyelesaikan permasalahan ini maka dibuat suatu analisis beberapa siswa/i sebagai alternatif dalam menggunakan metode promethee. Tujuan dari analisis ini adalah untuk menentuka kebutuhan-kebutuhan yang diperlukan dalam sebuah sistem pendukung keputusan.

Adapun kriteria yang harus dipenuhi dalam penentuan keahlian siswa/i ini adalah :

1. Alternatif Administrasi Perkantoran (A)

Setiap siswa harus mampu membuat arsip perkantoran, mahir mengetik dan mahir perhitungan excel

2. Alternatif Rekayasa Perangkat Lunak

\section{c) (i) (2)


Setiap siswa harus mampu membuat sebuah program aplikasi, mengedit program yang sudah ada dan mahir mengetik

3. Alternatif Multimedia

Setiap siswa harus mampu mendesain poster, mengedit video dan edit foto

Tabel Nama Siswa

\begin{tabular}{|c|l|}
\hline No & \multicolumn{1}{|c|}{ Nama } \\
\hline 1 & Aditya \\
\hline 2 & Bila \\
\hline 3 & Chici \\
\hline 4 & Dea \\
\hline 5 & Ema \\
\hline
\end{tabular}

Dengan menggunakan data siswa fungsi preferensi kriteria yang telah disisipkan beserta parameter dibandingkan dengan data siswa yang lain untuk menghasilkan nilai persial (promethee I). hasil dari proses promethee I yang akan berupa nilai leaving flow dan entering flow kemudian dikurangkan dan enghasilkan net flow yang berupa urutan lengkap atau promethee II.

\section{Alternatif bidang keahlian Administrasi Perkantoran}

Tabel kriteria dan nilai bobot

\begin{tabular}{|l|l|l|}
\hline No & Kriteria & Bobot \\
\hline 1 & Arsiparis $(\mathrm{C} 1)$ & 10 \\
\hline 2 & Mengetik (C2) & 10 \\
\hline 3 & Perhitungan Excel(C3) & 10 \\
\hline
\end{tabular}

Tabel nilai dari masing-masing kriteria

\begin{tabular}{|c|c|c|c|c|c|c|}
\hline \multirow{2}{*}{ No } & \multirow{2}{*}{ Kriteria } & \multicolumn{6}{|c|}{ Karyawan } \\
\cline { 3 - 7 } & & $\mathrm{A}$ & $\mathrm{B}$ & $\mathrm{C}$ & $\mathrm{D}$ & $\mathrm{E}$ \\
\hline 1 & C1 & 10 & 10 & 10 & 10 & 10 \\
\hline 2 & C2 & 9 & 8 & 9 & 10 & 7 \\
\hline 3 & C3 & 9 & 9 & 9 & 9 & 9 \\
\hline
\end{tabular}

Langkah menghitung nilai kriteria dengan metode promethee:

1. Memberi nilai pada setiap alternatif

2. Menghitung perbandingan nilai tiap kriteria sehingga akan didapat selisih $\mathrm{H}(\mathrm{d})$ dari kriteria dan index preferensi.

$$
\mathrm{P}(\mathrm{a} 1, \mathrm{a} 2)=\mathrm{P}\{\mathrm{f}(\mathrm{a} 1)-\mathrm{f}(\mathrm{a} 2)
$$

1. $\mathrm{f} 1=\mathrm{C} 1$

$\mathrm{f} 1(\mathrm{~A}, \mathrm{~B}) \longrightarrow \mathrm{d}=\mathrm{f}(\mathrm{a})-\mathrm{f}(\mathrm{b})$

$$
\begin{aligned}
& d=10-10 \\
& d=0
\end{aligned}
$$

\section{c) (1)(2)




$$
\operatorname{maka} H(d)=1
$$

$\mathrm{f} 1=\mathrm{C} 1$

f1 (B,A)

$$
\begin{gathered}
\longrightarrow=\begin{array}{l}
\mathrm{f}(\mathrm{b})-\mathrm{f}(\mathrm{a}) \\
\mathrm{d}=10-10 \\
\mathrm{~d}=0
\end{array}
\end{gathered}
$$$$
\operatorname{maka} \mathrm{H}(\mathrm{d})=1
$$

$\mathrm{f} 1=\mathrm{C} 2$

f1 $(\mathrm{A}, \mathrm{B})$

$$
\begin{gathered}
\longrightarrow=f(a)-f(b) \\
d=9-8 \\
d=1
\end{gathered}
$$$$
\text { maka } \mathrm{H}(\mathrm{d})=1
$$

$\mathrm{f} 1=\mathrm{C} 2$

f1 (B,A)

$$
\begin{aligned}
\mathrm{d}(\mathrm{f})-\mathrm{f}(\mathrm{a}) \\
\mathrm{d}=8-9 \\
\mathrm{~d}=-1
\end{aligned}
$$

maka $\mathrm{H}(\mathrm{d})=0$

$\mathrm{f} 1=\mathrm{C} 3$

f1 $(\mathrm{A}, \mathrm{B})$

$$
\begin{aligned}
\longrightarrow=f(a)-f(b) \\
d=9-9 \\
d=0
\end{aligned}
$$$$
\operatorname{maka} H(d)=1
$$

$\mathrm{f} 1=\mathrm{C} 3$

f1 (B,A)

$$
\begin{gathered}
\longrightarrow=\mathrm{f}(\mathrm{b})-\mathrm{f}(\mathrm{a}) \\
\mathrm{d}=9-9 \\
\mathrm{~d}=0
\end{gathered}
$$

maka $\mathrm{H}(\mathrm{d})=1$

$$
\begin{aligned}
& \mathrm{f} 1=\mathrm{C} 4 \\
& \mathrm{f} 1(\mathrm{~A}, \mathrm{~B}) \longrightarrow \mathrm{f} \longrightarrow \mathrm{f}(\mathrm{a})-\mathrm{f}(\mathrm{b}) \\
& \mathrm{d}=7-9 \\
& \mathrm{~d}=-2
\end{aligned}
$$

maka $\mathrm{H}(\mathrm{d})=0$

$\mathrm{f} 1=\mathrm{C} 4$

f1 (B,A)

$$
\begin{aligned}
& \longrightarrow= f(b)-f(a) \\
& d=9-7 \\
& d=2
\end{aligned}
$$

maka $\mathrm{H}(\mathrm{d})=1$

$\mathrm{f} 1=\mathrm{C} 5$

f1 $(\mathrm{A}, \mathrm{B})$

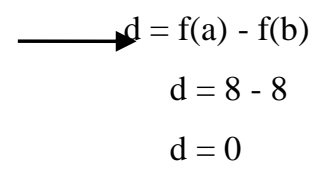

maka $\mathrm{H}(\mathrm{d})=1$

$\mathrm{f} 1=\mathrm{C} 5$

f1 (B,A)

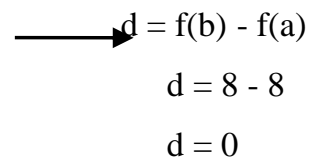

maka $\mathrm{H}(\mathrm{d})=1$

dan seterusnya sampai perhitungan selesai pada keseluruhan kriteria dan alternatif.

3. Langkah selanjutnya menghitung index multikriteria.

$\mathrm{k}$

$\delta(\mathrm{a}, \mathrm{b})=\sum \pi \mathrm{P}_{\mathrm{i}}(\mathrm{a}, \mathrm{b}) ; \forall \mathrm{a}, \mathrm{b} \varepsilon \mathrm{A}$

$\mathrm{i}=1$

$(\mathrm{A}, \mathrm{B})=1 / 10(1+1+1+0+1+0+1+1+1+1)=0,8$

\section{c) (i) (2)}

JURNAL WIDYA This work is licensed under a Creative Commons Attribution-NonCommercialShareAlike 4.0 International License. 
$(\mathrm{B}, \mathrm{A})=1 / 10(1+0+1+1+1+1+1+1+1+0)=0,8$

$(\mathrm{A}, \mathrm{C})=1 / 10(1+1+1+0+1+0+1+1+1+1)=0,8$

$(C, A)=1 / 10(1+1+1+1+1+1+1+0+1+0)=0,8$

$(\mathrm{A}, \mathrm{D})=1 / 10(1+0+1+1+1+0+1+1+1+0)=0,7$

$(\mathrm{D}, \mathrm{A})=1 / 10(1+1+1+0+1+1+1+0+1+1)=0,8$

$(\mathrm{A}, \mathrm{E})=1 / 10(1+1+1+0+1+1+1+1+1+1)=0,9$

$(\mathrm{E}, \mathrm{A})=1 / 10(1+0+1+1+1+0+1+0+1+0)=0,6$

Dan seterusnya sampai perhitungan selesai.sehingga didapat hasil promethee tahap I seperti pada tabel berikut ini: Tabel promethee tahap I

\begin{tabular}{|c|c|c|c|c|c|}
\hline & A & B & C & D & E \\
\hline A & - & 0.8 & 0.8 & 0.7 & 0,9 \\
\hline B & 0.8 & - & 0.7 & 0.7 & 1 \\
\hline C & 0.8 & 0.8 & - & 0.7 & 0.9 \\
\hline D & 0.8 & 0.9 & 0.9 & - & 0.9 \\
\hline $\mathrm{E}$ & 0.6 & 0.7 & 0.6 & 0.6 & - \\
\hline
\end{tabular}

4. Selanjutnya menghitung leaving flow

$$
\begin{aligned}
& \Phi^{+}(\mathrm{a})=\frac{1}{\mathrm{n}-1} \sum \delta(\mathrm{a}, \mathrm{x}) \times \varepsilon \mathrm{A} \\
& \mathrm{A}=1 /(10-1)(0.8+0.8+0.7+0.9)=2.4 \\
& \mathrm{~B}=1 /(10-1)(0.8+0.7+0.7+1)=2.311111 \\
& \mathrm{C}=1 /(10-1)(0.8+0.8+0.7+0.9)=2.4 \\
& \mathrm{D}=1 /(10-1)(0.8+0.9+0.9+0.9)=2.7 \\
& \mathrm{E}=1 /(10-1)(0.6+0.7+0.6+0.6)=1.966667
\end{aligned}
$$

5. Selanjutnya menghitung entering flow

$$
\begin{aligned}
& \Phi^{-}(\mathrm{a})=\frac{1}{\mathrm{n}-1} \sum \delta(\mathrm{x}, \mathrm{a}) \mathrm{x} \varepsilon \mathrm{A} \\
& \mathrm{A}=1 /(10-1)(0.8+0.8+0.7+0.6)=2.366667 \\
& \mathrm{~B}=1 /(10-1)(0.8+0.8+0.9+0,7)=2.577778 \\
& \mathrm{C}=1 /(10-1)(0.8+0.7+0.9+0.6)=2.466667 \\
& \mathrm{D}=1 /(10-1)(0.7+0.7+0.7+0.6)=2.166667 \\
& \mathrm{E}=1 /(10-1)(0.9+1+0.9+0.9)=2.9
\end{aligned}
$$

\section{cc) (1)(2)}

JURNAL WIDYA This work is licensed under a Creative Commons Attribution-NonCommercialShareAlike 4.0 International License. 
6. Menghitung net flow

$$
\begin{aligned}
& \Phi(a)=\Phi^{+}(a)-\Phi^{-}(a) \\
& A=2.4-2.366667 \quad=0.033333 \\
& B=2.311111-2.577778=-0.26667 \\
& C=2.4-2.466667 \quad=-0.06667 \\
& D=2.7-2.166667 \quad=0.533333 \\
& E=1.966667-2.9 \quad=-0.93333
\end{aligned}
$$

Setelah melakukan perhitungan maka diperoleh lah hasil promethee tahap II.

Tabel promethee tahap II

\begin{tabular}{|c|c|c|}
\hline Alternatif & Net Flow & Ranking \\
\hline A & 0.033333 & II \\
\hline B & -0.26667 & IV \\
\hline C & -0.06667 & V \\
\hline D & 0.533333 & I \\
\hline E & -0.93333 & III \\
\hline
\end{tabular}

Berdasarkan nilai net flow dari tabel promethee tahap II diperoleh nilai rangking karakter net flow, sehingga siswa yang mempunyai bidang keahlian administrasi perkantoran adalah Dea.

\section{Alternatif bidang keahlian Rekayasa Perangkat Lunak}

Tabel kriteria dan nilai bobot

\begin{tabular}{|l|l|l|}
\hline No & Kriteria & Bobot \\
\hline 1 & programer (D1) & 25 \\
\hline 2 & Mengetik (D2) & 25 \\
\hline 3 & Program editing(D3) & 25 \\
\hline
\end{tabular}

Tabel nilai dari masing-masing kriteria

\begin{tabular}{|c|c|c|c|c|c|c|}
\hline \multirow{2}{*}{ No } & \multirow{2}{*}{ Kriteria } & \multicolumn{5}{|c|}{ Karyawan } \\
\cline { 3 - 7 } & & A & B & C & D & E \\
\hline 1 & D1 & 22 & 20 & 25 & 25 & 24 \\
\hline 2 & D2 & 24 & 23 & 23 & 24 & 25 \\
\hline 3 & D3 & 20 & 20 & 22 & 19 & 25 \\
\hline
\end{tabular}

\section{Alternatif bidang keahlian Multimedia}

Tabel kriteria dan nilai bobot

\begin{tabular}{|l|l|l|}
\hline No & Kriteria & Bobot \\
\hline 1 & Video editing (E1) & 40 \\
\hline
\end{tabular}

\section{cc) () (2)}

JURNAL WIDYA This work is licensed under a Creative Commons Attribution-NonCommercialShareAlike 4.0 International License. 


\begin{tabular}{|l|l|l|}
\hline 2 & Foto editing (E2) & 30 \\
\hline 3 & Desain (E3) & 30 \\
\hline
\end{tabular}

Tabel nilai dari masing-asing kriteria

\begin{tabular}{|c|c|c|c|c|c|c|}
\hline No & \multirow{2}{*}{ Kriteria } & \multicolumn{5}{|c|}{ Karyawan } \\
\cline { 3 - 7 } & & A & B & C & D & E \\
\hline 1 & E1 & 40 & 40 & 40 & 35 & 25 \\
\hline 2 & E2 & 30 & 30 & 28 & 24 & 30 \\
\hline 3 & E3 & 28 & 28 & 30 & 30 & 20 \\
\hline
\end{tabular}

Berdasarkan perhitungan yang sama maka diperoleh hasil mengenai bidang keahlian siswa/i SMK Swasta Mulia Pratama berdasarkan tabel berikut ini:

Tabel perolehan bidang keahlian siswa/i

\begin{tabular}{|l|l|l|l|}
\hline No & \multicolumn{1}{|c|}{ Jenis Bidang Keahlian } & Net Flow & Nama \\
\hline 1 & Administrasi perkantoran & 0.5 & Dea \\
\hline 2 & Rekayasa Perangkat Lunak & 1.335 & Bila \\
\hline 3 & Multimedia & 1.84 & Ema \\
\hline
\end{tabular}

\section{Kesimpulan}

Adapun kesimpulan dari penelitian ini adalah sebagai berikut:

1. Penentuan bidang keahlian siswa/i adalah salah satu upaya untuk menempatkan siswa berada di kelas mana agar tidak salah jurusan.

2. Penerapan metode promethee dala bidang keahlian siswa SMK dilakukan masing-masing bidang. Hasil tersebut akan dirangking, nilai yang berada pada posisi paling besar akan disimpulkan bahwa siswa tersebut memiliki keahlian di bidang yang diuji tersebut.

\section{Referensi}

[1] Murdani, “METODE PROMETHEE,” vol. 8, pp. 51-56, 2019.

[2] kusrini, Konsep dan Aplikasi Sistem Pendukung Keputusan. ANDI Yogyakarta, 2007.

[3] Mahsa montajabiha, An Extended PROMETHE II Multi-Criteria Group Decision Making Technique Based on Intuitionistic Fuzzy Logic for Sustainable Energy Planning. 2016.

[4] A. Alinezhad, New Methods and Applications in Multiple Attribute Decision Making (MADM). 2019.

[5]_Nandang Mulyana, Agus Sulistyanto, Verdi Yasin (2021), Perancangan sistem informasi pengelolaan aset it berbasis web pada pt mandiri axa general insurance, "Jurnal Manajemen Informatika Jayakarta", E-ISSN : 2797-0930 (Online), P-ISSN : 2746-5985 (Print), Volume 1, Nomor 3, Juli 2021, halaman 243-257, DOI: 
10.52362/jmijayakarta.v1i3.498, URL Publikasi:

http://journal.stmikjayakarta.ac.id/index.php/JMIJayakarta/article/view/498

[6] Maulia Usnaini, Verdi Yasin, Anton Zulkarnain Sianipar (2021), Perancangan sistem informasi inventarisasi aset berbasis web menggunakan metode waterfall, "Jurnal Manajemen Informatika Jayakarta", E-ISSN : 2797 0930 (Online), P-ISSN : 2746-5985 (Print) Volume 1, Nomor 1,Februari 2021, halaman 36-55, DOI: 10.52362/jmijayakarta.v1i1.415, URL Publikasi: http://journal.stmikjayakarta.ac.id/index.php/JMIJayakarta/article/view/415

[7]_Putri Setiani, Ifan Junaedi, Anton Zulkarnain Sianipar, Verdi Yasin (2021), Perancangan sistem informasi pelayanan penduduk berbasis website di rw 010 Kelurahan Keagungan Kecamatan Tamansari - Jakarta Barat. "Jurnal Manajemen Informatika Jayakarta”, E-ISSN : 2797-0930 (Online), P-ISSN : 2746-5985 (Print) Volume 1, Nomor 1,Februari 2021, halaman 20-35, DOI: 10.52362/jmijayakarta.v1i1.414, URL Publikasi: http://journal.stmikjayakarta.ac.id/index.php/JMIJayakarta/article/view/414

[8] Ifan Junaedi, Dimas Abdillah, Verdi Yasin (2020) “Analisis Perancangan Dan Pembangunan Aplikasi Business Intelligence Penerimaan Negara Bukan Pajak Kementerian Keuangan RI", Journal of Information System, Applied, Management, Accounting and Research, e-ISSN: 2598-8719. p-ISSN: 2598-8700.Vol.4 No.3 (14 Agustus 2020) p88-101 http://journal.stmikjayakarta.ac.id/index.php/jisamar/article/view/249

[9] Anis Rohmadi, Verdi Yasin (2020) “Desain Dan Penerapan Website Tata Kelola Percetakan Pada CV Apicdesign Kreasindo Jakarta Dengan Metode Prototyping", Journal of Information System, Informatics and Computing._E-ISSN: 2597-3673 (Online), P-ISSN: 2579-5201 (Print) Vol. 4 No.1, June 22, 2020. Pp.70-85 http://journal.stmikjayakarta.ac.id/index.php/jisicom/article/view/210

[10] Septian Cahyadi, Verdi Yasin, Mohammad Narji, Anton Zulkarnain Sianipar (2020) “Perancangan Sistem Informasi Pengiriman Dan Penerimaan Soal Ujian Berbasis Web ( Studi Kasus: Fakultas Komputer Universitas Bung Karno)", Journal of Information System, Informatics and Computing. E-ISSN: 2597-3673 (Online), PISSN: 2579-5201 (Print) Vol. 4 No.1, June 22, 2020. Pp.1-16 http://journal.stmikjayakarta.ac.id/index.php/jisicom/article/view/199

[11] Ifan Junaedi, Ndaru Nuswantari, Verdi Yasin (2019) “Perancangan Dan Implementasi Algoritma C4.5 Untuk Data Mining Analisis Tingkat Risiko Kematian Neonatum Pada Bayi", Journal of Information System, Informatics and Computing. E-ISSN: 2597-3673 (Online), P-ISSN: 2579-5201 (Print) Vol. 3 No.1, February 13, 2019. Pp.29-44. http://journal.stmikjayakarta.ac.id/index.php/jisicom/article/view/203

[12] Verdi Yasin, Muhammad Zarlis, Tulus, Erna Budhiarti Nababan, Poltak Sihombing (2019) "Rancangan Miniatur Otomatisasi Bel Listrik Pada Gerbang Pintu Menggunakan Microkontroler Atmega8535", Journal of Information System, Informatics and Computing. E-ISSN: 2597-3673 (Online), P-ISSN: 2579-5201 (Print) Vol. 3 No. 1, February 13, 2019. Pp.13-20 http://journal.stmikjayakarta.ac.id/index.php/jisicom/article/view/68

[13]_Anggeri S. Nurjaman, Verdi Yasin (2020) “Konsep Desain Aplikasi Sistem Manajemen Kepegawaian Berbasis Web Pada PT. Bintang Komunikasi Utama", Journal of Information System, Informatics and Computing._EISSN: 2597-3673 (Online), P-ISSN: 2579-5201 (Print) Vol. 4 No. 2, December 28, 2020. Pp.143-174 http://journal.stmikjayakarta.ac.id/index.php/jisicom/article/view/363

[14] Verdi Yasin, Azhar Ahmad Riza, Rumadi Hartawan (2017) “Pengembangan Aplikasi Pemulihan Layanan Bencana Sistem Informasi Peneriman Negara Bukan Pajak Online Di Lingkungan Kementerian Keuangan Republik Indonesia", Journal of Information System, Informatics and Computing. E-ISSN: 2597-3673 (Online), P-ISSN: 2579-5201 (Print) Vol. 1 No. 1, September 20, 2017. Pp.33-56.

http://journal.stmikjayakarta.ac.id/index.php/jisicom/article/view/4 